\title{
AUDIOBOOK ISLAMI \\ UNTUK PENYANDANG DISABILITAS SLB KATEGORI A
}

\author{
Maya Rini Handayani \\ Fakultas Dakwah dan Komunikasi Universitas Islam Negeri Walisongo \\ Semarang \\ Email:m4y4_b4nd4@yahoo.com
}

\begin{abstract}
The Indonesian government has launched a 9-year compulsory education program for all students in Indonesia. The word "all" should have been touching all levels of society including the blind students. However, the fact shows different condition. Many schools still refuse to accept the blind students. In addition, some facilities like braille books for the blind students are also still limited while these books become the main pillar of education. They still become such "luxury stuffs" for the blind students in Indonesia.

The cost of producing Braille books equals with fourfold financing regular books. This is because the Braille books need heavier papers, approximately 120 grams for every sheet of paper. To resolve this problem is by creating an audiobook or better known as a "voiced book" for the blind students. The extraordinary school (SLB) of category $A$ is an outstanding school specifying for the blind students in Semarang who desperately need an audiobook.

This audiobook has many benefits for the blind students of SLB category $A$. Firstly, it facilitates the students to "read" a book through the hearing sense. Secondly, it minimizes the cost of school expenditures in the book procurement both regular books for teachers or braille books for students. At last, it supports the government program of campaigning "paperless office".
\end{abstract}

Keywords : audiobook, slb-a, education

\begin{abstract}
Abstrak
Pemerintah Indonesia telah meluncurkan program wajib belajar 9 tahun bagi semua siswa di Indonesia. Kata "semua" seharusnya menyentuh semua lapisan masyarakat termasuk para pelajar tunanetra. Namun, fakta menunjukkan kondisi yang berbeda. Banyak sekolah masih menolak untuk menerima siswa tunanetra. Selain itu, beberapa fasilitas seperti buku braille bagi siswa tunanetra juga masih terbatas sementara buku-buku ini menjadi pilar utama pendidikan. Mereka masih menjadi seperti "barang mewah" untuk siswa tunanetra di Indonesia.
\end{abstract}


Biaya produksi buku Braille sama dengan pembiayaan empat kali lipat buku biasa. Hal ini karena buku Braille perlu kertas lebih berat, sekitar 120 gram untuk setiap lembar kertas. Untuk mengatasi masalah ini adalah dengan menciptakan buku audio atau yang lebih dikenal sebagai "buku bersuara" untuk siswa tunanetra. Sekolah luar biasa (SLB) dari kategori A adalah sekolah luar biasa menentukan bagi siswa tunanetra di Semarang yang sangat membutuhkan buku audio.

Audiobook ini memiliki banyak manfaat bagi siswa tunanetra dari kategori SLB A. Pertama, memfasilitasi siswa untuk "membaca" buku melalui indera pendengaran. Kedua, meminimalkan biaya pengeluaran sekolah dalam pengadaan buku baik buku biasa untuk guru atau buku braille bagi siswa. Akhirnya, mendukung program pemerintah mengkampanyekan "kantor tanpa kertas".

Kata Kunci: audiobook, slb-a, pendidikan

\section{A. PENDAHULUAN}

Pendidikan adalah hak setiap insan manusia. Begitu pula dengan insan manusia di Indonesia atau warga negara Indonesia (WNI), baik itu warga yang normal fisiknya ataupun warga yang mempunyai keterbatasan atau disabilitas ${ }^{1}$. Ketentuan tersebut tertuang dalam:

1. Ayat 1 pasal 31 UUD 1945, yaitu "Tiap-tiap warga negara berhak mendapatkan pendidikan".

2. Ayat 1 pasal 6 UURI No 4 tahun 1997, yaitu "Setiap penyandang cacat berhak memperoleh pendidikan pada semua satuan, jalur, jenis, dan jenjang pendidikan"

3. Pasal 11 UURI No. 4 tahun 1997, yaitu " Setiap penyandang cacat mempunyai kesamaan kesempatan untuk mendapatkan pendidikan pada satuan jalur, jenis, dan jenjang pendidikan sesuai dengan jenis dan derajat kecacatannya"

${ }^{1}$ Disabilitas atau Cacat (bahasa Inggris: disability) dapat bersifat fisik, kognitif, mental, sensorik, emosional, perkembangan atau beberapa kombinasi dari ini. Menurut Organisasi Kesehatan Dunia (WHO) disabilitas adalah istilah yang meliputi gangguan, keterbatasan aktivitas, dan pembatasan partisipasi. Gangguan adalah sebuah masalah pada fungsi tubuh atau strukturnya; suatu pembatasan kegiatan adalah kesulitan yang dihadapi oleh individu dalam melaksanakan tugas atau tindakan, sedangkan pembatasan partisipasi merupakan masalah yang dialami oleh individu dalam keterlibatan dalam situasi kehidupan. Jadi disabilitas adalah sebuah fenomena kompleks, yang mencerminkan interaksi antara ciri dari tubuh seseorang dan ciri dari masyarakat tempat dia tinggal, http://id.wikipedia.org/wiki/Disabilitas 
4. Pasal 12 UURI No 1997, yaitu "Setiap lembaga pendidikan memberikan kesempatan dan perlakuan yang sama kepada penyandang cacat sebagai peserta didik pada satuan, jalur, jenis, dan jenjang pendidikan sesuai dengan jenis dan derajat kecacatan serta kemampuannya"

Dari pasal-pasal tersebut jelas terlihat bahwa penyandang disabilitas mempunyai hak yang sama dengan WNI lainnya untuk memperoleh pendidikan sesuai dengan jenis dan derajat kecacatan serta kemampuannya. Artinya setiap penyandang disabilitas dapat memperoleh kesempatan belajar yang sama dengan WNI lainnya (walaupun di sekolah yang khusus ataupun sekolah umum).

Para siswa penyandang disabilitas menuntut ilmu di sekolah khusus dengan tujuan agar mereka dapat memperoleh kesempatan yang sama dengan siswa lainnya. Namun ada beberapa hal yang terlupakan oleh para penanggung jawab pendidikan yaitu minimnya fasilitas buku khusus bagi mereka seperti buku braille ${ }^{2}$. Disamping buku braille mahal harganya, materi untuk pendidikan dengan menggunakan huruf ini masih terbatas jumlahnya. Padahal buku-buku pendidikan terutama pendidikan agama sangatlah penting bagi penyandang disabilitas di tingkat sekolah dasar, menengah pertama dan menengah atas.

Pemerintah Indonesia dalam membuat kurikulum pendidikan masih berpihak kepada siswa yang normal fisiknya. Hal ini terlihat dari ragam/jenis buku, materi pendidikan bahkan fasilitas yang diperuntukkan bagi pendidikan, sangat jarang yang menyentuh lingkup penderita disabilitas. Sekolah luar biasa (SLB) adalah sekolah khusus yang diperuntukkan bagi siswa disabilitas untuk menuntut ilmu. Beberapa sekolah tersebut diberi kode kategori untuk para penyandang disabilitas. Tabel 1 di bawah ini menjelaskan jenis kategori tersebut.

\begin{tabular}{|c|c|c|c||}
\hline Kategori & Nama & Jenis disabilitas & Pengertian \\
\hline \hline $\mathrm{A}$ & tunanetra & disabilitas fisik & tidak dapat melihat; $\underline{\text { buta }}$ \\
\hline \hline $\mathrm{B}$ & tunarungu & disabilitas fisik & tidak dapat mendengar; $\underline{\text { tuli }}$ \\
\hline
\end{tabular}

${ }^{2}$ Huruf Braille adalah sejenis sistem tulisan sentuh yang digunakan oleh orang buta. Sistem ini diciptakan oleh seorang Perancis yang bernama Louis Braille yang buta dari kecil. Ketika berusia 15 tahun, Braille membuat suatu tulisan tentara untuk memudahkan tentara untuk membaca ketika gelap. Tulisan ini dinamakan huruf Braille. Namun ketika itu huruf Braille belum mempunyai huruf W, http://id.wikipedia.org/wiki/Braille 


\begin{tabular}{|c||c|c|l||}
\hline \hline $\mathrm{C}$ & tunawicara & disabilitas fisik & tidak dapat berbicara; bisu \\
\hline \hline $\mathrm{D}$ & tunadaksa & disabilitas fisik & cacat tubuh \\
\hline \hline $\mathrm{E} 1$ & tunalaras & disabilitas fisik & cacat suara dan nada \\
\hline \hline $\mathrm{E} 2$ & tunalaras & disabilitas mental & $\begin{array}{l}\text { sukar mengendalikan emosi dan } \\
\text { sosial. }\end{array}$ \\
\hline $\mathrm{F}$ & tunagrahita & disabilitas mental & $\begin{array}{l}\text { cacat pikiran; lemah daya tangkap; } \\
\text { idiot }\end{array}$ \\
\hline \hline $\mathrm{G}$ & tunaganda & disabilitas ganda & $\begin{array}{l}\text { lenderita cacat lebih dari satu } \\
\text { kecacatan } \\
\text { (yaitu cacat fisik dan mental) }\end{array}$ \\
\hline
\end{tabular}

Tabel 1 Kode Sekolah Luar Biasa

Permasalahan ketidaktersediaan buku berhuruf braille ini yang membuat penulis berkeinginan untuk membuat solusi alternatif baru. Solusi tersebut menggunakan media perangkat lunak/software yaitu berupa andiobook (buku bersuara) atau buku digital berbasis audio untuk pembelajaran siswa tunanetra atau siswa SLB kategori A.

Sekolah Luar Biasa (SLB) kategori A sangat sedikit jumlahnya, bahkan di Semarang hanya ada satu yaitu sekolah yang terletak di jalan Puri Anjasmoro Blok K-8 Kecamatan Semarang Barat, Kota Madya Semarang. Sekolah tersebut $100 \%$ siswanya adalah penderita blind disability atau cacat buta. Sekolah ini dikelola oleh yayasan kristen. Seratus persen gurunya adalah pemeluk kristen, sedangkan siswanya sebanyak $90 \%$ adalah muslim. Sebenarnya sekolah ini sudah mempunyai beberapa buku braille namun buku braille yang berisi pengetahuan atau pendidikan Islam belumlah ada. Hal tersebut wajar terjadi sebab sekolah tersebut dikembangkan oleh yayasan kristen.

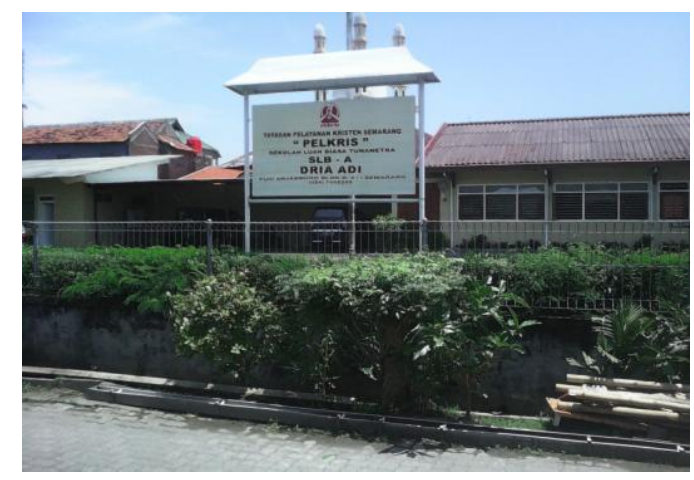

Gambar 1. SLB Kategori A 
Pada sekolah tersebut, di tahun 2014, terdapat 12 siswa SD yang terdiri dari 6 siswa dan 6 siswi yang berusia antara 6-13 tahun. Sekolah tersebut mempunyai satu kepala sekolah, delapan guru (dengan tiga guru diantaranya adalah penyandang disabilitas tunanetra, 2 orang diantaranya penyandang totally blind atau buta total dan 1 orang penderita low vision atau pandangan rendah) dan 13 murid (6 putra dan 7 putri) yang terdiri dari 12 siswa SD dan 1 siswi SMP. Kegiatan belajar mengajar di SLB kategori A hampir mirip dengan sekolah umum lainnya, hanya ditambah dengan mapel praktek pengenalan. Mapel praktek pengenalan adalah mapel yang memberikan pengetahuan pengenalan baik lingkungan, benda dan cara melakukan sebuah pekerjaan. Contohnya adalah bagaimana caranya menuangkan air dari teko ke gelas, cara masuk dan keluar ke dan dari kamar mandi (KM), cara mengenakan baju rumah/sekolah secara mandiri, cara mengenal dan menghapal rute jalan di lingkungan sekolah dan sebagainya.

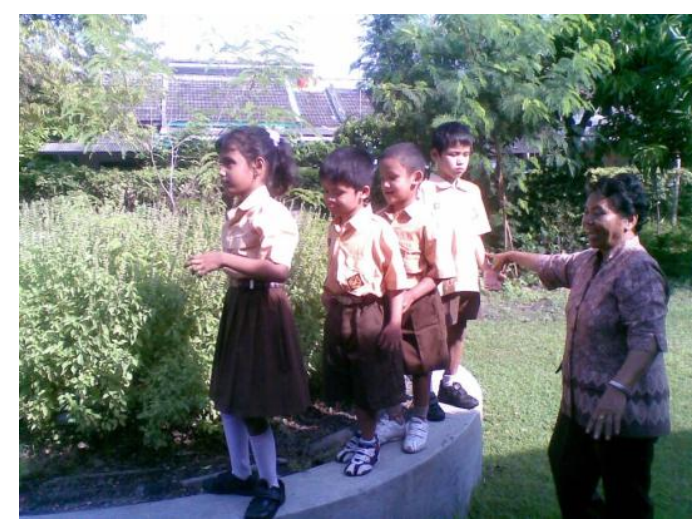

Gambar 2. Pengenalan Lingkungan oleh Siswa SLB Kategori A

Gambar di atas adalah salah satu kegiatan di sekolah tentang pengenalan lingkungan. Siswa diajak untuk mengenal lingkungan dengan cara berjalan dan meraba kondisi lingkungan luar. Siswa di latih untuk mempertajam indera lain seperti penciuman dan kepekaan atau insting. Kegiatan dilakukan di sekitar halaman dan lingkungan sekolah. Kegiatan tersebut di pandu oleh seorang guru awas (bukan penyandang disabilitas), namun tidak menutup kemungkinan di pertengahan pelajaran juga di pandu guru yang tunanetra untuk mempertajam penglihatan menggunakan perasaan.

Sekolah SLB-A sebenarnya bukanlah sekolah yang tidak mempunyai buku untuk siswa berkebutuhan khusus. Sekolah sudah mempunyai beberapa buku mata pelajaran (mapel) menggunakan huruf braille namun 
masih terbatas jumlah dan judulnya (termasuk ketiadaan buku braille yang berisi pengetahuan agama Islam). Selain keterbatasan, ketidakefektifan terjadi terutama bila mapelnya adalah hafalan. Kondisi seperti ini sering dikeluhkan oleh guru dan orang tua siswa.

Siswa mengalami kesulitan jika mapelnya adalah hafalan karena secara visual mereka tidak dapat melihat dan membayangkan sehingga membutuhkan sebuah media pembelajaran yang dapat diputar berulangulang untuk membantu mempermudah menghafal mapel. Selain itu tebalnya buku braille (mengingat kertas untuk buku braille berbeda dengan kertas biasa, karena satu lembar kertas untuk buku braille tebalnya sama dengan selembar kertas karton) menyulitkan dan memberatkan siswa untuk membawa.

Audiobook sendiri mempunyai pengertian sebagai sebuah rekaman kata-kata yang diucapkan narrator atau reader berdasarkan kata-kata yang terdapat pada buku cetak. Namun pembacaan audiobook tidak harus selalu sama persis dengan versi cetaknya. Narrator atau reader dapat dilakukan oleh semua orang tanpa kecuali, lebih idealnya adalah seseorang yang memiliki variasi suara lebih dari satu. Hal tersebut dibutuhkan bila dalam buku cetak tersebut terdapat ilustrasi percakapan. Audiobook itu sendiri mempunyai sejarah yang cukup panjang. Diawali pada tahun 1931, Kongres Amerika menetapkan program audiobook (buku bicara atau buku bersuara) yaitu sebuah program yang diperuntukkan membantu orang tunanetra yang tidak bisa membaca buku cetak/teks. Program ini disebut "Proyek Buku untuk Orang Buta." Buku bersuara pertama kali dikembangkan oleh Yayasan Orang Buta Amerika pada tahun 1932

Pada tahun 1933 dimulailah proses penerbitan audiobook secara massal. Pada tahun yang sama, seorang antropolog bernama JP Harrington mencatat sejarah suku Indian secara lisan, rekaman tersebut di simpan pada disc aluminium. Pada tahun 1935, Kongres menyetujui audiobook didistribusikan secara umum. Pada tahun 1992, Perpustakaan Nasional Amerika memberikan pelayanan untuk penyandang tunanetra dan penyandang cacat lainnya yang disebut dengan National Library Service.

Pada perpustakaan tersebut terdapat jutaan buku untuk lebih dari 700.000 pendengar cacat. Semua rekaman pada audiobook direkam oleh narrator profesional. Pada tahun 1996 Audio Publishers Association mendirikan Audie Award untuk audiobook yang berprestasi atau bagus, penghargaan ini setara dengan Piala Oscar. Nominasi Audie Award 
diumumkan setiap tahun pada bulan Januari. Para pemenang diumumkan pada acara gala pesta di musim semi, bertepatan dengan Book Expo Amerika.

Sebenarnya teknik pembacaan pada audiobook ada dua macam, yaitu teknik unabridged audiobook dan abridged audiobook. Unabridged audiobook. adalah pembacaan kata demi kata dari sebuah buku cetak, sedangkan abridged audiobook adalah pembacaan kata-kata yang tidak sesuai dengan buku cetaknya namun tidak mengurangi tujuan kalimatnya. Teknik kedua biasanya dilakukan untuk menghemat biaya produksi. Sebenarnya teknik pembacaan pada audiobook ada dua macam, yaitu teknik unabridged audiobook dan abridged audiobook. Unabridged audiobook adalah pembacaan kata demi kata dari sebuah buku cetak, sedangkan abridged audiobook adalah pembacaan kata-kata yang tidak sesuai dengan buku cetaknya namun tidak mengurangi tujuan kalimatnya. Teknik kedua biasanya dilakukan untuk menghemat biaya produksi.

\section{B. PEMBAHASAN}

Audiobook yang penulis buat untuk sekolah tersebut adalah audiobook Islami. Audiobook Islami tersebut berisi kisah-kisah $25 \mathrm{Nabi}$ dan Rasul serta cerita tentang ilmuwan muslim. Ke 25 Nabi dan Rasul tersebut adalah nabi Adam As, nabi Idris As, nabi Nuh As, nabi Hud As, nabi Shaleh As, nabi Ibrahim As, nabi Luth As, nabi Ismail As, nabi Ishak As, nabi Ya'kub As, nabi Yusuf As, nabi Ayyub As, nabi Syu'aib As, nabi Musa As, nabi Harun As, nabi Zulkifli As, nabi Daud As, nabi Sulaiman As, nabi Ilyas As,nabi Ilyasa As, nabi Yunus As, nabi Zakariya As, nabi Yahya As, nabi Isa As dan nabi Muhammad Saw sebagai penutup kisah di audiobook.

Sedangkan ilmuan muslim yang dijadikan file audiobook sebanyak 28 nama ilmuan. Nama-nama ilmuan tersebut antara lain, yang pertama adalah Abu Abdullah Muhammad Ibnu Jabir Sina Ar-Raqqi Al-Harrani As-Sabi Al Battani atau lebih dikenal dengan Al Battani. Di masyarakat Barat, Al Battani dikenal dengan nama Albatenius. Al Battani menemukan perhitungan tahun matahari. Al Battani menyatakan Bumi mengelilingi tata surya dalam 365 hari 5 jam dan 24 detik. Ilmuan kedua adalah Abu Warwan Abdul Malik Ibnu Zuhr, di Barat dikenal dengan Avenzoar atau Abumeron. Ibnu Zuhr terkenal sebagai ahli bedah jantung pada masanya.

Ilmuan ke tiga adalah Abu Kamil Shuja Ibnu Aslam Ibnu Muhammad Ibnu Shuja atau lebih dikenal dengan nama Ibnu Shuja. Ibnu 
Shuja adalah seorang ahli berhitung yang terkenal di masanya. Ibnu Shujalah yang menyempurnakan aljabar karya Al Khawarizmi. Ilmuan yang ke empat adalah Ja'far Ibnu Muhammad Abu Ma'shar Al Balkhi, dikenal pula dengan nama Abulmazar. Abu Ma'shar merupakan muslim yang ahli dalam ilmu perbintangan. Ilmuan ke lima adalah Abu Abdullah Muhammad ibnu Al-Idrisi Al Qurtubi atau dikenal dengan nama Al-Idrisi Al-Quturbi. Di dunia Barat dikenal dengan nama Edrisi atau Dreses. AlIdrisi adalah pembuat peta bola dunia menggunakan bahan perak. Bola tersebut mempunyai berat $400 \mathrm{~kg}$. Al-Idrisi menggambarkan enam buah benua di bola dunia yang dibuatnya.

Baik audiobook kisah Nabi dan Rasul serta ilmuan muslim, keduanya bersumber dari sebuah buku yang penulis jadikan acuan untuk pembuatan audiobook. Pembacaan untuk perekaman teks menjadi audio (audiobook) dibaca dari cover buku depan hingga cover buku belakang. Semua tulisan baik huruf maupun angka harus di baca untuk proses perekaman.

Jenis audiobook yang penulis gunakan adalah kombinasi antara unabridged audiobook dan abridged audiobook. Pembacaan unabridged audiobook atau pembacaan dengan teknik kata per kata sesuai dengan buku cetak, penulis lakukan pada saat tulisan di buku cetak berisi kalimat informasi. Pembacaan abridged audiobook atau pembacaan yang tidak sesuai kata di buku cetak namun tidak boleh melenceng dari arti di buku tersebut, penulis lakukan pada saat muncul ilustrasi seperti pada buku ilmuwan muslim.

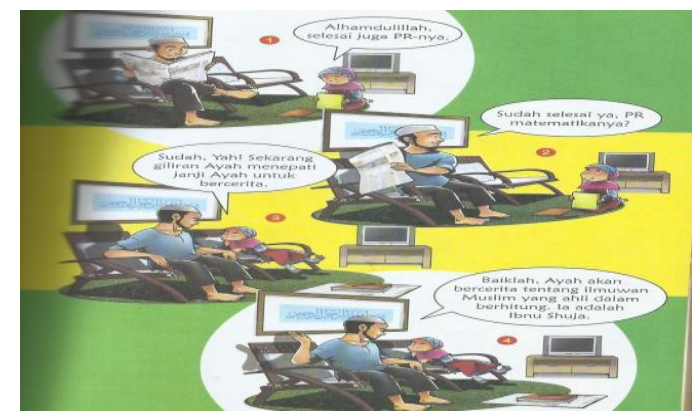

Gambar 3 Tulisan Berbentuk Ilustrasi Ilmuan Ibnu Shuja

Pada gambar di atas, tulisan berbentuk ilustrasi percakapan antara ayah dan anak perempuannya. Anak perempuan tersebut telah mengerjakan PR (pekerjaan rumah) Matematikanya. Setelah selesai, dia menagih janji ayahnya untuk menceritakan ilmuan muslim yang pandai berhitung yaitu Ibnu Shuja. Untuk proses perekaman ini, penulis 
menggunakan metode abridged audiobook dengan bentuk vokal suara yang berbeda untuk ayah dan anak.

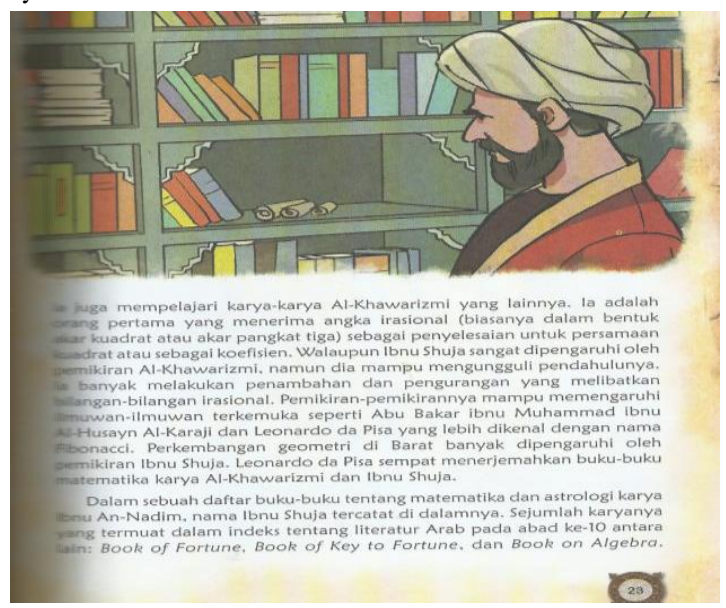

Gambar 4 Tulisan Berbentuk Teks Ilmuan Ibnu Shuja

Teknik untuk membuat audiobook yang baik ada beberapa cara. Yang pertama, dengan menggunakan sebuah aplikasi praktis yang digunakan untuk merekam file audio. Nama aplikasi tersebut adalah Read for The Blind. Read for the Blind umum dipergunakan masyarakat Thailand. Aplikasi tersebut merupakan kerja sama antara Google, Samsung Galaxy, SCB Bank, dan Thai telco AIS sehingga tidak mengherankan jika aplikasi ini berkembang dan dipergunakan oleh masyarakat Thailand. Sedangkan di Indonesia belum ada kesadaran dari pemerintah untuk mendanai provider membuat aplikasi seperti itu di ponsel pintar, padahal pengguna ponsel pintar di Indonesia sangatlah banyak. Oleh sebab itu, penulis menggunakan cara ke dua dan ke tiga. Cara kedua adalah dengan merekam buku teks tersebut menggunakan alat bantu (tool) sebuah recorder yang menghasilkan output suara berekstensi mp3. Alat tersebut dijual bebas di Indonesia dan biasanya digunakan oleh para peneliti untuk merekam data hasil wawancara. Kelebihan alat ini adalah ekstensi simpan yang berbentuk mp3, umumnya file audio raw (mentah) yang tersimpan berekstensi wav. Cara yang ketiga adalah menggunakan komputer atau laptop yang terinstal software Adobe Audition dan terhubung dengan microphone aktif untuk merekam file tersebut.

Software Adobe Audition selain digunakan untuk merekam juga dapat digunakan untuk mengedit file audiobook yang tersimpan. Adobe Audition versi 1.5 merupakan salah satu versi software untuk semua komputer 32 bit. Semua jenis Adobe sangat membutuhkan space (ruang) di 
harddisk yang cukup besar mengingat versi Adobe digunakan untuk pengolahan audio, video dan image. Untuk Adobe Audition ini membutuhkan temporary space yang cukup besar untuk editing file audio, biasanya Adobe akan secara otomatis menyarankan drive D atau E (jika mempunyai 3 drive yaitu C, D, E) yang mempunyai space kosong lebih besar.

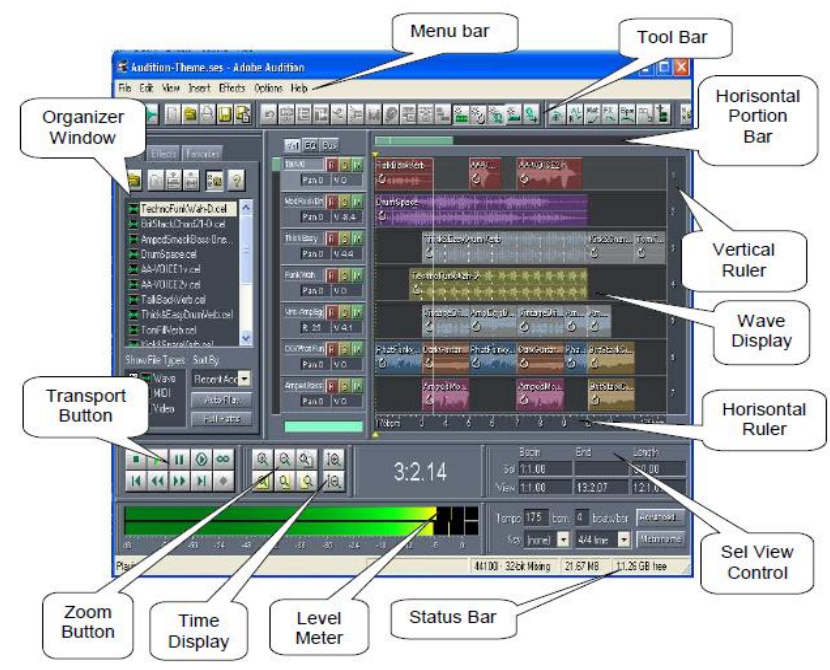

Gambar 5. Menu Adobe Audition

Untuk membuat file audiobook yang harus dilakukan adalah mempersiapkan komputer/laptop yang mendukung, microphone sebagai alat bantu perekaman dan software Adobe Audition untuk merekam dan mengedit. Jika menggunakan Adobe Audition, reader/narator (pembaca buku cetak) dapat memilih sample rate ${ }^{3}$ dan ekstensi file. Ekstensi disebut juga dengan format file yang biasanya tertulis sebagai akhiran file. Sebagai contoh microsoft word, maka semua file yang disimpan akan berkestensi .doc (titik doc) yang menunjukkan bahwa file tersebut berbentuk document. Untuk file audiobook ini, semua file disimpan dalam bentuk berekstensi mp3. Mp3 atau singkatan dari MPEG-1 Audio Layer 3 adalah salah satu format berkas pengodean suara yang memiliki kompresi yang baik (meskipun bersifat $\underline{\text { lossy }}{ }^{4}$ ) sehingga ukuran berkas bisa memungkinkan

\footnotetext{
${ }_{3}$ Sample rate adalah rata-rata jumlah sampel yang diperoleh dalam satu detik atau sampel per detik (https://en.wikipedia.org/wiki/Sampling_(signal_processing) \#Sampling_rate).

${ }^{4}$ Lossy adalah jenis pemampatan atau kompresi data dengan menghilangkan bagian data yang tidak terlalu penting dengan menggunakan algoritma tertentu (https://id.wikipedia.org/wiki/Kompresi_data) 
menjadi lebih kecil. Berkas ini dikembangkan oleh seorang insinyur Jerman bernama Karlheinz Brandenburg. MP3 memakai pengodean $\underline{\text { Pulse }}$ Code Modulation (PCM). MP3 mengurangi jumlah bit yang diperlukan dengan menggunakan model psychoacoustic untuk menghilangkan komponen-komponen suara yang tidak terdengar oleh manusia.

Untuk membuat file audio atau merekam buku teks untuk menjadi file audio maka pada Adobe Audition pilih tampilan multitrack view yang terletak diantara edit view dan $c$ project view.

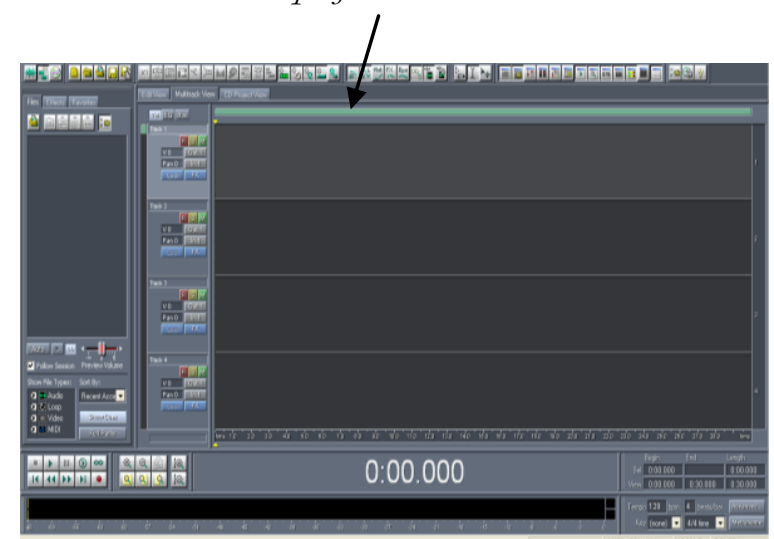

Gambar 6. Multitrack View

Terlihat timer (pewaktu) pada Adobe Audition masih menunjuk pada angka 0.00.000 yaitu keadaan default (standar). Timer tersebut akan bergerak jika tombol record 1 dinyalakan atau tombol play $\mid$ dinyalakan ketika ada file audio yang ingin diperdengarkan untuk di edit.

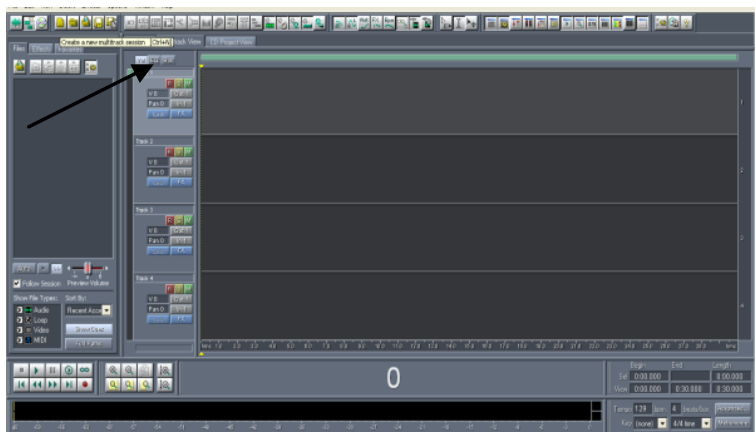

Gambar 7. Create A New Multitrack

Create a new multitrack digunakan untuk merekam file audio. Ketika pilihan create a new multitrack tersebut dipilih maka akan muncul sample rate yang harus dipilih untuk menentukan kualitas dari file audio yang dihasilkan. 


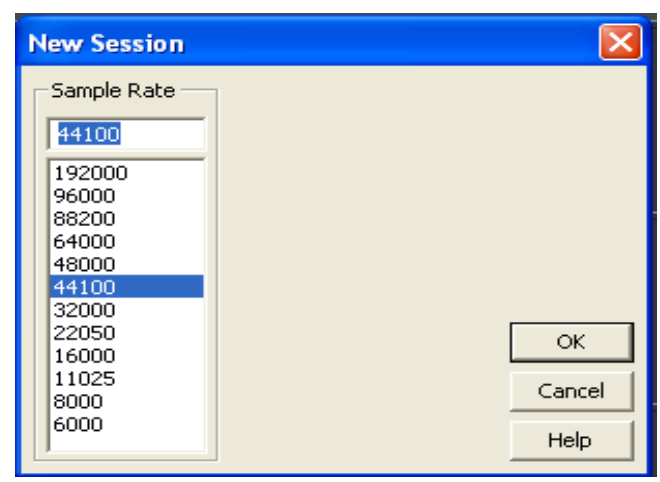

Gambar 8. Create A New Multitrack

Sample rate yang digunakan untuk proses perekaman adalah 44100 sample per detik untuk kualitas cd (compact disk) atau standar. Setelah memilih sample rate maka menekan tombol record 0 . Kemudian simpan file dengan nama sesuai dengan judul materi, agar mudah dalam mencari dan menyimpan. Untuk mempermudah membedakan file yang satu dengan file yang lain maka proses penyimpanan di awali dengan angka 001 dan seterusnya, ekstensi yang digunakan adalah mp3 agar file mudah disimpan karena kecil ukurannya serta mudah dimainkan di semua software aplikasi audio.

Pada saat proses perekaman, tidak semua proses berjalan lancar. Untuk memudahkan atau mengantisipasi ketidaklancaran proses perekaman maka sebelum dimulai, penulis melakukan sebagai berikut:

1. Jika pada buku teks hanya terdapat gambar tanpa tulisan maka hendaknya menambah sendiri tulisan (dengan tidak merubah makna dan isi cerita buku)

2. Memodifikasi tulisan pada buku teks yang membingungkan atau kurang bisa dipahami (dengan tidak merubah makna dan isi cerita buku)

3. Berlatih mengeja per huruf untuk nama yang muncul di artikel/buku untuk menghindari terbiasa membaca nama secara keseluruhan, misal jika di buku teks terdapat nama pengarang "Maya Rini Handayani" berarti harus di baca em // a // ye // a // er// i // en // i // ha// a // en// de// a // ye// a // en // i //.

4. Untuk mempermudah mengedit dan memperhalus suara rekaman, maka untuk memulai (start recording) dan mengakhiri (end recording) di beri jarak waktu 
5. Jika terdapat kesalahan dalam membaca maka langsung diberhentikan proses perekamannya, kemudian diulang kembali dari yang salah agar proses pengeditan menjadi mudah.

Walaupun sudah diantisipasi untuk meminimalisir kesalahan, tetap saja dalam proses pembuatan terdapat beberapa kendala. Kendala tersebut antara lain:

\section{Pengisi Suara}

Kendalanya berupa jenis suara dari reader. Kadang kala hasil suara tidak sebagus yang diinginkan sebab reader bukanlah seorang dubber. Jika suara tidak sesuai dengan yang diinginkan maka harus melalui proses rekaman ulang. Ketepatan posisi microphone juga mempengaruhi dalam proses rekaman. Suara yang terlalu besar pitch ${ }^{5}$ nya pada saat perekaman menyebabkan desible ${ }^{6}$ selalu naik, sehingga perlu melakukan proses rekaman ulang.

\section{Banyaknya noise}

Noise atau derau tidak akan muncul jika proses perekaman dilakukan di studio yang kedap suara. Disebabkan penulis tidak mempunyai studio sendiri sehingga sering kali proses perekaman terhambat oleh suara gangguan yang masuk, seperti suara deru motor, percakapan orang, detik jam, batuk orang, deru pesawat yang lewat dan sebagainya. Jika muncul gangguan maka reader harus memberhentikan sejenak bacaannya kemudian mengulang kembali dari teks pada saat pembacaan terakhir.

Bahkan noise juga dapat muncul disebabkan oleh recorder yang sensitif, seperti klik tombol mulai dan berhenti akan ikut terekam di file audio. Antisipasinya adalah setelah klik start maka diberi jeda terlebih dahulu dan setelah perekaman akhir selesai maka diberi jeda waktu sebelum menekan tombol stop. Fungsi dari jeda tersebut akan sangat bermanfaat ketika proses editing menggunakan Adobe Audition berjalan. Noise internal tersebut dapat dipotong sehingga hasil akhir file audiobook tidak akan muncul noise.

\footnotetext{
${ }^{5}$ Pitch adalah tinggi rendah nada dalam suatu bunyian. Pitch berkaitan dg getaran yg dihasilkan oleh instrument maupun suara manusia. Bila getarannya semakin banyak maka nada yg dihasilkan akan semakin tinggi. Pada vokal, pitch berkaitan dengan intonasi. Kemampuan intonasi adalah kesanggupan seseorang dalam membedakan mana suara yang fals dan yang tidak.

${ }^{6}$ Desibel (lambang Internasional $=\mathrm{dB}$ ) adalah satuan untuk mengukur intensitas suara. Satu desibel ekuvalen dengan sepersepuluh $\underline{B e l}$. Huruf "B" pada dB ditulis dengan huruf besar karena merupakan bagian dari nama penemunya, yaitu $\underline{B e l l}$
} 


\section{Waktu perekaman suara}

Noise yang sering muncul menyebabkan penulis mempunyai strategi tersendiri untuk merekam. Waktu yang dipilih adalah tepat tengah malam sekitar pukul 00.00 WIB. Saat dimana orang-orang terlelap tidur, yang ada hanya kesunyian adalah waktu yang tepat untuk proses rekam suara. Namun harus diingat jika kita ingin merekam suara tepat tengah malam, usahakan setelah bangun tidur untuk mengatur pola suara terlebih dahulu. Sebab orang yang bangun tidur akan memiliki kecenderungan suara membesar dari biasanya, sehingga menyebabkan pitch dan nada menjadi berbeda.

\section{Perubahan suara}

Kendala lainnya adalah perubahan suara yang disebabkan karena sakit flu, suara menjadi membesar dan nafas menjadi pendek. Hal ini akan menyebabkan terganggu proses rekaman karena akan menyebabkan pitch suara menjadi berbeda. Sangat tidak disarankan jika dalam satu file terdapat perbedaan suara karena pengaruh pitch. Berbeda jika memang dalam satu file ada dua jenis suara yang berbeda.

Setelah proses perekaman, hal yang harus dilakukan selanjutnya adalah proses editing. Editing merupakan proses yang digunakan untuk menggabungkan beberapa file audio yang telah di rekam. Seorang reader belum tentu dapat membaca teks secara keseluruhan dalam satu kali take untuk sebuah file. Oleh sebab itu proses editing menjadi sangat penting. Editing juga digunakan untuk meminimalisir noise yang muncul saat proses perekaman.

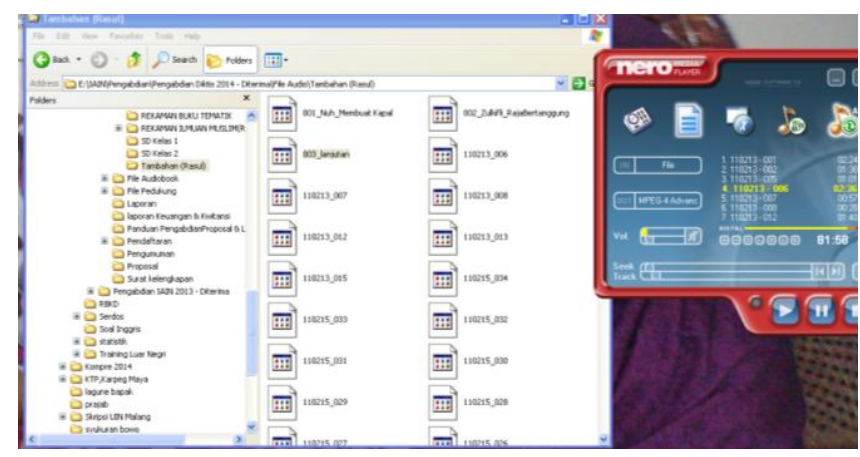

Gambar 9. Merubah Nama File

Editing dilakukan dengan dua cara yang berbeda. Untuk perekaman menggunakan recorder, maka nama file yang ditransfer ke laptop/komputer akan bernama standar seperti 110213_015, 110213_016, 110213_017 dan 
seterusnya. Untuk mempermudah proses editing di Adobe Audition maka file-file tersebut kita perdengarkan terlebih dahulu sekaligus mengecek file audio. Kemudian per file tersebut diganti namanya sesuai dengan urutan perekaman dan judul.

Untuk mempermudah maka perubahan nama file disesuaikan dengan judul tema atau sub tema, misalnya 110213_015 menjadi 007_Nabi_Adam_Nenek_Moyang_Umat_Manusia yang mana ini adalah judul utama dari bab pertama tentang Nabi Adam. Jika 110213_016 adalah file lanjutan dari 110213_015 maka file tersebut berganti nama menjadi 008_Nabi_Adam_Nenek_Moyang_Umat_Manusia_lanjutan. Akan tetapi jika file tersebut bukanlah lanjutan dari file sebelumnya maka penamaan menggunakan urutan dan sub tema menjadi 008_Nabi_Adam_Teman_Hidup begitu juga dengan file-file lain yang direkam menggunakan recorder.

Berbeda dengan perekaman menggunakan komputer/laptop dengan bantuan software Adobe Audition. File yang terekam langsung dapat disimpan dengan nama sesuai kebutuhan dan berkekstensi mp3. Selanjutnya adalah menggabungkan file-file audio yang terpotong tersebut menggunakan Adobe Audition yang disebut dengan proses mix down. Filefile audio yang akan di mix down, diletakkan pada track 1, 2 dan seterusnya. Namun dapat juga diletakkan dalam satu track berjajar seperti gambar di bawah ini.

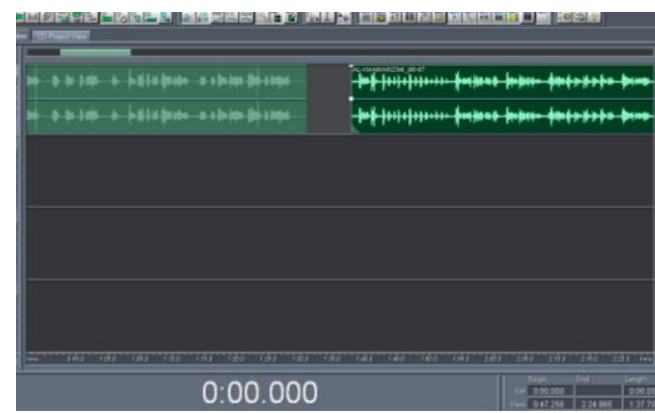

Gambar 10. Beberapa File dalam Satu Track

Pada saat proses creating mix down, kecepatan mix down file tergantung pada kecepatan komputer/laptop, jumlah file yang di mix down, dan panjang pendek file atau lebih tepatnya ukuran file (dalam bentuk mega byte atau kilo byte). Pada saat proses mix down akan membutuhkan waktu yang sedikit lebih lama, walaupun begitu jangan pernah menekan tombol cancel karena akan membatalkan terbentuknya file hasil mix down kecuali 
jika memang akan dbatalkan maka silahkan ditekan cancel. Hasil mix down akan terlihat seperti di bawah ini:

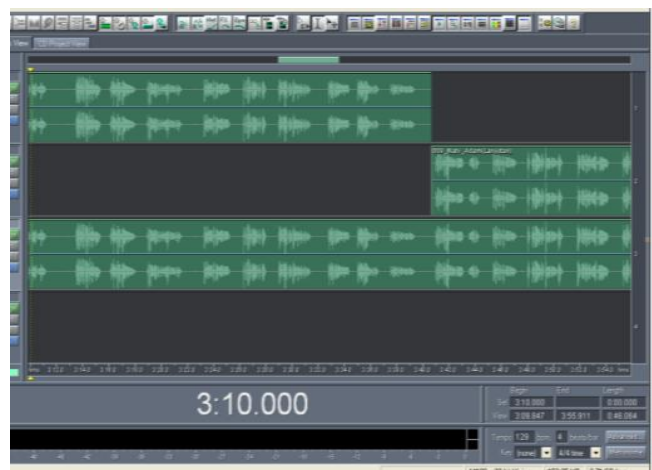

Gambar 11. Hasil Mix Down

Pada gambar di atas terlihat hasil mix down yang terletak di track terakhir atau track ke tiga. Hasil mix down merupakan gabungan antara file di track pertama dan track ke dua. File hasil mix down di simpan dengan nama sesuai isi dari file, harus berurutan untuk memudahkan pemutaran file-file audiobook dan berekstensi mp3 untuk mendapatkan file yang berukuran kecil. Kemudian muncul proses saving (simpan) mp3 seperti di bawah ini.

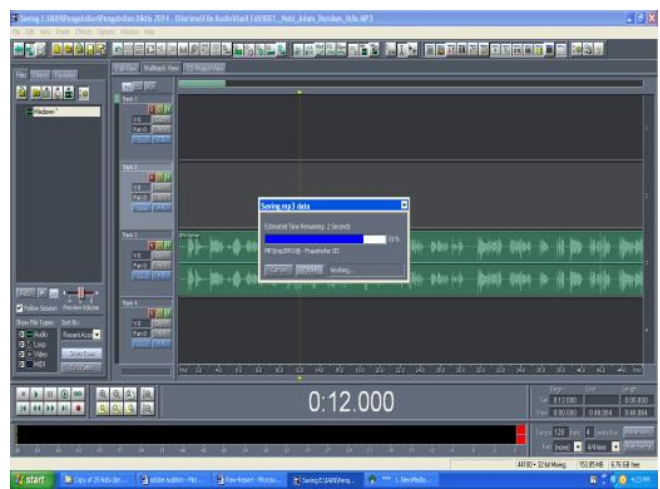

Gambar 12. Proses Simpan

Kendala yang mungkin muncul pada saat proses editing audiobook adalah :

1. Harus ekstra hati-hati mendengarkan per kata yang muncul di file audio, sebab jika tidak cermat maka apabila ada beberapa teks yang hilang kita tidak akan mengetahuinya

2. Pada saat proses editing, konsentrasi sangatlah dibutuhkan sebab pada proses ini membutuhkan beberapa panca indera yang bekerja 
sekaligus dalam satu waktu yaitu pendengaran untuk mendengarkan file audiobook dan mata untuk menelusuri teks dari buku

Audiobook yang sudah dibuat dan diedit harus melalui tahap pengujian sebelum diimplementasikan kepada penyandang tunanetra. Menurut Widyanahar terdapat 5 pengujian (yaitu pengujian unit, integrasi, beta, regresi dan stress) untuk sebuah pekerjaan rekayasa perangkat lunak (software engineering), namun karena pembuatan audiobook bukanlah pembuatan software engineering seutuhnya maka tidak semua pengujian digunakan. Pengujian yang digunakan adalah :

1. Pengujian unit, untuk pengujian ini adalah mendengarkan satu per satu file audiobook kemudian di cek terdapat kesalahan bacaan atau tidak, kesesuaian kata dengan buku, kesesuaian letak kalimat yang diucapkan dengan urutan kalimat di buku. Jika dalam pengujian terdapat ketidaksesuaian maka harus remake atau pembuatan ulang namun tidak secara total

2. Pengujian integrasi, pengujian integrasi dilakukan ketika beberapa file rekaman yang terpotong-potong (disebabkan karena kesalahan pada saat proses perekaman) akan digabungkan menjadi satu. Jika pada saat dilakukan penggabungan terdapat ketidaksesuaian maka harus dilakukan pengulangan untuk file yang menyebabkan terjadinya kesalahan.

3. Pengujian beta, pengujian ini adalah pengujian yang dilakukan di hadapan para guru dan kepala sekolah. Pada pengujian ini membutuhkan masukan atau feedback dari para guru dan kepala sekolah. Yang mana jika terdapat masukan untuk perbaikan kualitas audiobook maka harus dilakukan sebelum diimplementasikan pada siswa SLB.

4. Pengujian regresi, pengujian terakhir adalah regresi. Pengujian yang dilakukan pada saat implementasi terhadap siswa. Siswa juga berhak memberikan masukan mengingat merekalah yang akan menggunakan audiobook tersebut.

Setelah tahap perancangan, perekaman, pembuatan dan pengujian audiobook terselesaikan maka audiobook yang berisi kisah-kisah $25 \mathrm{Nabi}$ dan Rasul serta cerita tentang ilmuwan muslim dapat dipergunakan oleh siswa SLB kategori A. Siswa SLB kategori A sangat senang dengan adanya audiobook Islami sebab selama mereka menuntut ilmu di sekolah tersebut belum pernah ada mapel yang berhubungan dengan agama Islam. Bahkan di sekolah tersebut tidak ada satupun audiobook yang membahas tentang 
Islam. Mereka mengetahui tentang ajaran agama Islam hanya dari orang tua atau wali mereka.

\section{KESIMPULAN}

Audiobook atau buku bersuara Islami mempunyai beberapa manfaat bagi siswa SLB kategori A, yaitu :

1. Mempermudah siswa tunanetra untuk "membaca" buku-buku Islam melalui panca indera pendengaran

2. Mempermudah proses belajar dan mengajar siswa tunanetra terutama pengetahuan tentang Islam

3. Memperkecil biaya pengeluaran sekolah dalam pengadaan buku baik buku biasa (bagi guru) ataupun buku braille (bagi siswa)

4. Memperkecil biaya pengeluaran sekolah dalam pengadaan buku baik buku biasa (bagi guru) ataupun buku braille (bagi siswa)

5. Mendukung kegiatan pemerintah dalam memperbaharui lingkungan yang mencanangkan kampanye "paperless office".

\footnotetext{
7 Paperless office adalah suatu usaha mengurangi penggunaan kertas, namun bukan meniadakan penggunaan kertas sama sekali (karena kita hampir tidak mungkin atau masih belum hidup tanpa ketas dalam kegiatan sehari-hari) dengan menggunakan konsep $3 \mathrm{R}$ (Reduce, Reuse, Recycle), http://takpenting.wordpress.com/2012/12/01/paperless-dantantangannya/
} 


\section{DAFTAR PUSTAKA}

Anonim, Disabilitas http://id.wikipedia.org/wiki/Disabilitas, diakses 26 September 2016

Anonim, Braille http://id.wikipedia.org/wiki/Braille, diakses 26 September 2016

Anonim, UU dan RUU/UUD 45, http://dpr.go.id/uu-dan-ruu/uud45, diakses 26 September 2016

Anonim, undang-undang-uu-ri-no-4-tahun-1997-tentang-penyandangcacat, http://kpai. go.id/hukum/undang-undang-uu-ri-no-4-tahun1997-tentang-penyandang-cacat, diakses 26 September 2016

Anonim, Media Teknologi Audiobook, http://www.scribd.com/doc/ 24555959/Media-Teknologi-Audio-Book\#scribd, diakses 10 September 2016

Anonim, Gantt Chart, http://id.wikipedia.org/wiki/Henry_Gantt, diakses 10 September 2016

Anonim, Derau, http://id.wikipedia.org/wiki/Derau, diakses 11 September 2016

Anonim, Sampling_(signal_processing)\#Sampling_rate, https://en.wikipedia.org/wiki/Sampling_(signal_processing)\#Samp ling_rate, diakses 29 September 2016

Anonim, Apa itu Sample rate dan Bit Rate dalam Audio, https://jejakbrowsing.wordpress.com/2011/03/22/apa-itu-samplerate-dan-bit-rate-dalam-audio, diakses 15 September 2016

Anonim, Pitch dan Nada, http://instrukturmusik.blogspot.com/2011/09/pitch-dan-nada.html, diakses 16 September 2016

Anonim, Desibel, http://id.wikipedia.org/wiki/Desibel, diakses 16 September 2016

Anonim, MP3, http://id.wikipedia.org/wiki/MP3, diakses 17 September 2016

Anonim, Kompresi Data, https://id.wikipedia.org/wiki/Kompresi_data, diakses 30 September 2016

Fatin, Cahya Sri, 2013, "Penemuan Terbebat Ilmuan Muslim: Kisab Penemuan Hebat yang Mengubah Wajah Dunia”, Nectar Ensiklopedia

Handayani, Maya Rini, 2006, "Pencarian File Audio Berdasarkan Energi Ratarata, Laju Perpotongan pada Titik Nol dan Rasio Periode Keheningan", Tesis Universitas Gadjah Mada Yogyakarta

Hendrata, Tata, Peduli Lingkungan Melalui Paperless, http:/ / takpenting.wordpress.com/2012/12/01/paperless-dantantangannya/, diakses 26 September 2016

Hemdi, Yoli dan Novia, Rina, 2010, "25 Nabi dan Rasul Utusan Allab", Zikrul Kids - Zikrul Hakim 
Lu, Guojun, 1999, "Multimedia Database Management System", Artech House, Boston London

Widyanahar, Nur Ali, 2003, "Manajemen Proyek Sistem Informasi untuk Para Engineer dan Profesional', PT Elex Media Komputindo

Wong, Yue Ling, 2005, "Chapter 4 Fundamental Digital Audio", Department of Computer Science and Department of Art, Wake Forest University. 